\title{
HISTOPATHOLOGICAL STUDY OF LESIONS OF UMBILICUS
}

\section{Pathology \\ Dr. Medha P. Kulkarni \\ Associate professor, Pathology Department, Government Medical College, Miraj.}

\section{Dr. Alka V. Gosavi}

\section{Dr Kshama G. Darunde*}

Associate professor and Head, Department of Pathology, Government Medical College, Miraj.

\section{Junior Resident, Pathology Department, Government Medical College, Miraj. \\ *Corresponding Author}

\section{ABSTRACT}

Background: A variety of lesions either congenital or acquired affect the umbilicus. We present histopathological study of 55 umbilical lesions over a period of 40 months.

Material and Methods: Histopathological features of 55 umbilical lesions were analysed. Data of patients was obtained from the hospital records. There were 45 adult and 10 pediatric patients.

Results: The most common lesion was umbilical hernia constituting 43 cases. We had six cases of vitellointestinal duct remnants (VDR), two cases each of umbilical granuloma and tuberculosis and one case each of patent urachus and epidermal cyst.

Conclusion: Although rare, every lesion of the umbilicus needs histopathological examination since certain lesions like umbilical granuloma can be managed conservatively while others like VDR or umbilical hernia need surgical intervention. Also dormant tuberculosis can be diagnosed on histopathological examination of hernial sac.

\section{KEYWORDS}

\section{Umbilical polyps, Meckel diverticulum, umbilical granuloma}

\section{INTRODUCTION:}

The umbilicus is a relatively weak depression in the anterior abdominal wall at the level of the disc between L3-L4 vertebrae. ${ }^{1}$ Congenital lesions more commonly manifest in children and young adults and include anomalies of VDR like Meckel diverticulum, umbilical sinus, umbilical polyp and urachal anomalies like patent urachus, urachal cyst etc. ${ }^{2,3}$ Acquired umbilical lesions include umbilical granuloma, umbilical hernia etc. Lesions of umbilicus are rare but it is important to investigate every lesion since some can be managed conservatively while others need surgical intervention. ${ }^{4,5,6}$ Also certain lesions like tuberculosis (TB) or malignancy may be first detected in hernial sacs. ${ }^{7,8,9,10}$ Hence this study was undertaken to analyze the histophathological and clinical features of umbilical lesions in a tertiary care hospital.

\section{MATERIALAND METHODS:}

Fifty-five umbilical lesions were included in the study. Clinical details of the patients like age, sex and presenting symptoms were noted. The specimens were fixed in $10 \%$ formalin. Careful gross examination of the specimens was done. Representative sections from the specimen were submitted for tissue processing. Sections were stained with hematoxylin and eosin. Microscopic examination was done. Gross, microscopy and clinical features were correlated to arrive at a final diagnosis.

\section{RESULTS:}

We studied a total of 55 umbilical lesions from January 2017 to April 2020. During this period the total number of surgical specimens received was 9136 and umbilical lesions contributed 55(0.6\%). Umbilical hernia was the most common lesion encountered which accounted for 43 out of 55 cases ( $78.18 \%$ ) affecting 41 adults and two children. Clinically patients presented with painless mass at the umbilicus. There were six cases with seven VDR lesions viz six umbilical polyps and one Meckel diverticulum affecting five children and one adult. Two patients, both less than one year old presented with fleshy, bright red umbilical mass that proved to be umbilical granuloma on histopathological examination. There were two cases of tuberculosis and one case each of patent urachus and epidermal inclusion cyst.

\section{DISCUSSION:}

Umbilical lesions are rare and very few studies have been reported in the literature. Histopathological study of umbilical lesions is helpful in deciding the management of the patients, especially in pediatric age group where an umbilical granuloma can be treated conservatively by silver nitrate cauterization while an umbilical polyp needs surgical removal $^{2}$. Also, a nodule near umbilicus could be sister Joseph nodule prompting a thorough search for the primary tumor.

There were 45 adults and ten children. Gaopande et al have reported 10 adult and five pediatric patients in their study of 15 cases. ${ }^{11}$ Details of umbilical lesions encountered are presented in Table 1.

Table No 1. Types of umbilical lesions

\begin{tabular}{|l|l|l|}
\hline $\begin{array}{l}\text { Serial } \\
\text { no }\end{array}$ & Umbilical lesions & $\begin{array}{l}\text { Number with } \\
\text { percentage }\end{array}$ \\
\hline 1 & Umbilical hernia & $42+1^{*}(78.18)$ \\
\hline 2 & $\begin{array}{l}\text { Vitello intestinal duct remnant (Umbilical } \\
\text { adenoma, Umbilical polyp, Meckel } \\
\text { diverticulum) }\end{array}$ & $7(12.72 \%)$ \\
\hline 3 & Patent urachus & $1(1.81 \%)$ \\
\hline 4 & Umbilical granuloma & $2(3.63 \%)$ \\
\hline 5 & Tuberculosis & $1+1^{*}(3.63 \%)$ \\
\hline 6 & Epidermal inclusion cyst & $1(1.81 \%)$ \\
\hline
\end{tabular}

* Patient presented with hernia, microscopy of hernial sac revealed Tuberculosis

The most common lesion was umbilical hernia affecting 41 adults and two children. There were 24 males and 17 females. All our adult patients with umbilical hernia clinically presented with painless mass at the umbilicus which increased in size with coughing. Umbilical hernia results from conditions that cause stretching and thinning of the midline raphe such as pregnancy, obesity and liver disease with cirrhosis. Due to the risk of strangulation surgical repair is the choice of treatment. ${ }^{12}$ In our study one male patient had alcoholic liver disease with ascites, that might have contributed to umbilical hernia. Two females patients noticed umbilical hernia during pregnancy which was subsequently repaired in postpartum period.

The gross specimens were composed of hernial sac and variable amount of adipose tissue. On microscopy only one case showed features of tuberculosis. No specific lesion was noted in rest of the cases.

Congenital hernia was seen in two children aged four and six years. In both the cases, the swelling was present since birth. It was otherwise symptomless except for an increase in size on crying.

During fetal development the midgut communicates widely with the yolk sac. The vitellointestinal duct usually becomes obliterated by $10^{\text {th }}$ 
week of embryonic life and subsequently disappears completely. Anomalies of vitellointestinal duct are seen in approximately $2 \%$ of population and include

1) Meckel diverticulum - persistence of the intestinal end of vitelline duct

2) Umbilical polyp-persistence of the distal end of vitelline duct

3) Umbilical fistula- persistence of entire duct from ileum to umbilicus

4) Vitelline duct cyst- partial obliteration of duct

5) Vitelline band- fibrous cord connecting the wall of small intestine with umbilicus

Meckel diverticulum is the most common VDR and also the most common congenital anomaly of gastrointestinal tract ${ }^{3,4,5}$. In our study we had total seven VDR anomalies; six umbilical polyps and one Meckel diverticulum affecting five children and one adult patient who had umbilical polyp as well as Meckel diverticulum. Umbilical polyps presented as small cherry red lesions. (Fig. 1)

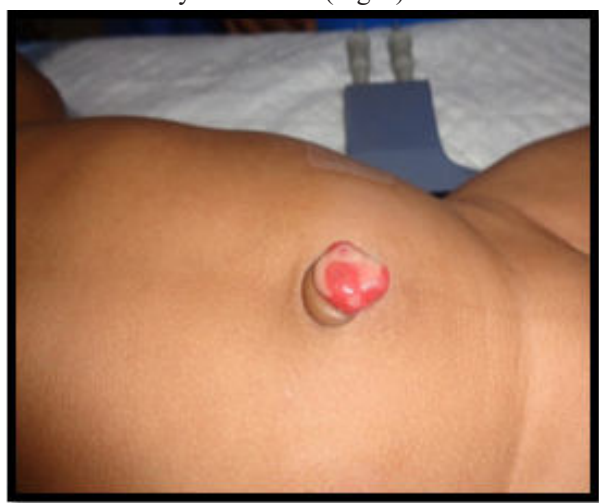

Fig 1 Clinical photograph of umbilical adenoma

Microscopy showed polypoidal mass lined by small intestinal mucosa (Fig.2).

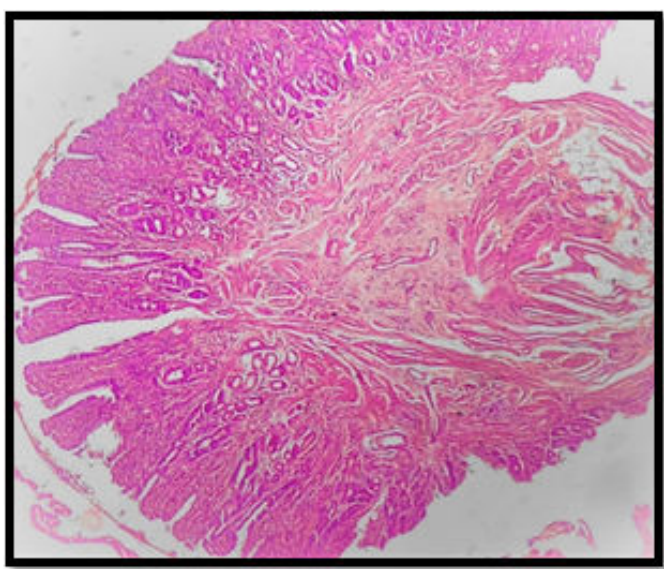

Fig 2- Umbilical polyp lined by intestinal mucosa (H\&E x 100x)

In two cases the mass showed heterotopic gastric mucosa. Umbilical polyps are small polypoid excrescences of intestinal mucosa lining the vitellointestinal duct. The size ranges from $0.5-2 \mathrm{~cm}$. Grossly the lesions present as bright red glistening masses with smooth surface. The treatment of umbilical polyps is surgical. The close differential diagnosis is umbilical granuloma which is discussed in subsequent paragraph.

The adult patient with VDR had both umbilical polyp and Meckel diverticulum. Patient was symptomatic only for umbilical polyp which was present since birth. Meckel diverticulum was detected on ultrasonography. We received three $\mathrm{cm}$ long Meckel diverticulum along with small segment of ileum. External surface was unremarkable. Microscopy of Meckel diverticulum revealed wall of small intestine lined by small intestinal mucosa. No heterotopic pancreatic or gastric mucosa was identified.

Gaopande et al have reported two VDR remnants, one Meckel diverticulum and one umbilical adenoma in their study of 15 cases.
An umbilical granuloma is a salmon pink colored friable mass, 3 $10 \mathrm{~mm}$ in size, usually presenting in neonates with seropurulent discharge. On microscopy it reveals granulation tissue composed of proliferating capillaries, fibroblasts and myofibroblasts. As against umbilical polyps, umbilical granulomas respond to silver nitrate cauterization and do not need surgery. ${ }^{5,6,13}$ In our study, there were two cases of umbilical granuloma affecting a 23 day old and a two month old male child. Both presented with fleshy red umbilical mass and were confirmed as umbilical granulomas on microscopy. Gaopande et al have reported three cases of umbilical granuloma in their study. ${ }^{11}$ Gross appearance of umbilical polyp and umbilical granuloma is similar but histopathology and management is altogether different, highlighting the role of histopathology in umbilical lesions.

The abdomen is the fourth most common site of involvement in extrapulmonary tuberculosis after lymph nodes, bones and genitourinary tract. It broadly includes tuberculous enterocolitis, tuberculous peritonitis and tuberculous lymphadenitis. ${ }^{14}$ Hernial sacs are likely to get involved in abdominal TB. Datey et al have reported an incidental finding of TB in the hernial sac of paraumbilical hernia while Vashista $\mathrm{M}$ et al have reported TB in inguinal hernia. ${ }^{7.8}$ In the present study we came across a case of TB in the hernial sac of a 60 year old lady with umbilical hernia. Patient presented with umbilcal hernia only and had no signs and symtoms of TB. Microscopy of the excised hernial sac revealed focus of necrosis with calcification and surrounded by epithelioid cells and fibrosis. (Fig.3)

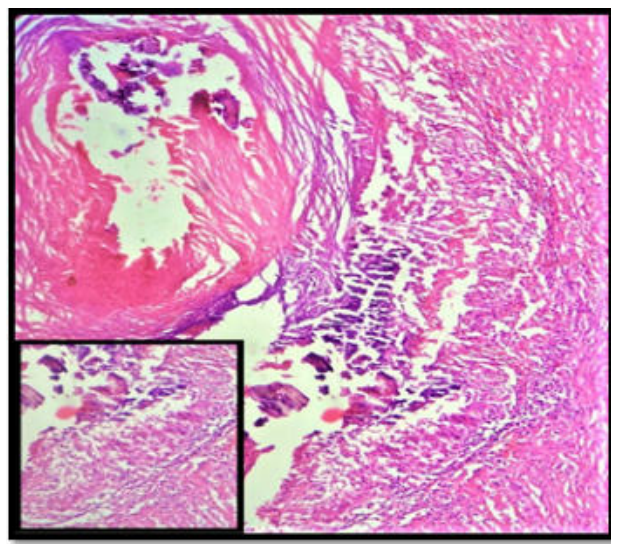

Fig 3 Hernial sac showing focus of necrosis surrounded by epithelioid cells, lymphocytes and fibrosis with calcification (H\&E x 400x)

The diagnosis of TB was done on histopathological examination of the hernial sac which would have gone otherwise unnoticed for a longer period. The other case of tuberculosis in our study was a 26 year old lady with history of laparoscopic appendicectomy three weeks back. Patient presented with pain in abdomen. Clinically umbilical port infection was suspected and tissue from the same revealed features of caseating tuberculosis

Peritoneal tuberculosis can involve the umbilicus and the manifestations include slit like smiling appearance with loss of umbilical hollow, puckering of umbilicus, umbilical erythema of fecal fistula.

Wang $\mathrm{T}$ et al found one malignancy in 800 inguinal and 7 cases in 576 abdominal wall hernial sacs. A large retrospective study of over 22186 hernias at Mayo clinic showed presence of metastatic cancer in $0.07 \%$ of patients highlighting the importance of histopathological examination of every excised hernial sac.

The urachus and urachal remnants represent failure of obliteration of the allantois that connects the urinary bladder to the umbilicus. It normally obliterates after birth and presents as midline umbilical ligament. ${ }^{3}$ Urachal defects are rare with urachal cysts being the most common anamoly occurring in approximately $1 / 5000$ births. ${ }^{16,1}$

We had a single case of patent urachus. The patient was 20 years female, who presented with passage of urine from the umbilicus during micturition. Serial sections of the excised specimen revealed cord like structure with fibrous obliteration. Microscopy showed multiple channels lined by urothelium with a muscular wall confirming it as urachal remnant (Fig. 4) 


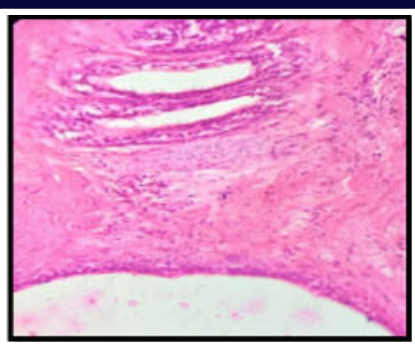

Fig 4 -Patent urachus showing multiple channels lined by transitional epithelium (H\&E x 400x)

Gaopande et al reported two cases of urachal abnormalities associated with abscess formation. ${ }^{11}$

Shruthi et al reported a single case with all three remnants, vitellointestinal duct, urachus and ligamentum venosum. ${ }^{17}$

Siow et al have reported abdominal tuberculosis affecting urachal remnant, a rare occurance. ${ }^{18}$

In the present study, there was a single case of epidermal inclusion cyst in a 35 years female. The clinical diagnosis was umbilical granuloma. Gross examination showed a cyst measuring $1.5 \mathrm{~cm}$ in diameter. Microscopy confirmed epidermal cyst. Epidermal cyst involving umbilicus is rare. McClennathan et al reported only seven cases of umbilical epidermoid cyst over a period of 17 years. ${ }^{19}$

\section{CONCLUSION}

Histopathological examination of every specimen of umbilical lesion is necessary. Lesions like umbilical granuloma and umbilical polyp have similar clinical presentation but definitive diagnosis on histopathology allows proper treatment. Also dormant tuberculosis can be diagnosed on histopathological examination of hernial sac.

\section{REFERENCES}

1. Das, A. (2019). Umbilical Lesions: A Cluster of Known Unknowns and Unknown Unknowns. Cureus, 11(8). https://doi.org/10.7759/cureus.5309

2. Ezejiofor, I., Ugwu, J., Ndukwe, C., Madubuike, K., \& Ozor, N. (2018). Umbilical Polyp; an Anomaly of Omphalomesenteric Duct Remnant from Birth in a 3-Year-old Male Child: A Case Report and Review of Literature. Medical Journal Of Dr. D.Y. Patil Vidyapeeth, 11(2), 175-177.

3. Sadler, T. Langman's medical embryology (13th ed.). Wolters Kluwer.

4. Sharma, D (2014). Umbilical Discharge and Its Management in Adults-Rare Presentatation. IOSR Journal Of Dental And Medical Sciences, 13(7), 45-48. https://doi.org/10.9790/0853-13744548

5. Gulia, S., M, L., Kamidi, V., SP, A., \& Sinha, P. (2015). Omphalomesenteric Duct Remnant: Umbilical Polyp- Clinically Mimicking Umbilical Granuloma. International Journal OfHealth Sciences And Reasearch, 5(7), 515-516.

6. Karagüzel, G., \& Aldemir, H. (2016). Umbilical Granuloma: Modern Understanding of Etiopathogenesis, Diagnosis, and Management. Journal Of Pediatrics And Neonatal Care, 4(3)

7. Datey, S. Charles, N Vashishtha, R, \& Patel, S. (2015). TUBERCULOSIS IN THE SAC OF PARAUMBILICAL HERNIA. Journal Of Evolution Of Medical And Dental Sciences, 4(96), 16201-16202. https://doi.org/10.14260/jemds/2015/2381

8. Vashista, M., Singhal, N., Verma, M., Deswal, S., \& Mathur, S. (2012). Abdominal Tuberculosis In A Hernial Sac: A Rare Presentation. The Internet Journal Of Surgery, 28(2). https://doi.org/10.5580/2ae4

9. Wang, T., \& Vajpeyi, R. (2013). Hernia sacs: is histological examination necessary?. Journal Of Clinical Pathology, 66(12), 1084-1086. https://doi.org/10.1136/jclinpath2013-201734

10. Nicholson, C. P., Donohue, J. H., Thompson, G. B., \& Lewis, J. E. (1992). A study of metastatic cancer found during inguinal hernia repair. Cancer, 69(12), 3008-3011. https://doi.org/10.1002/1097-0142(19920615)69:12<3008:-aidcncr2820691224>3.0.co;2-8

11. Gaopande, V., Deshmukh, S., Khandeparkar, S., Suryavanshi, M., \& Patil, V. (2015). Clinical and histopathological profile of lesions of umbilicus. Medical Journal OfDr. D. Y. Patil University, 8(2), 179-181.

12. Williams, N., Bulstrode, C., O'Connell, P., Bailey, H., \& Love, R. Bailey \& Love's short practice of surgery (26th ed.).2013. Taylor and Francis Group

13. Miyagi, H., Honda, S., Minato, M., Okada, T., Hatanaka, K. C., \& Taketomi, A. (2016). Impact of umbilical polyp resection: A report and literature review. African journal of paediatric surgery: AJPS, 13(4), 196-198

14. Bhende, Y., \& Deodhare, S. (2002). General Pathology and Pathology of systems (6th ed., pp. 883-934). Popular prakashan.

15. Pant N, Roy Choudhary S, Gupta A et al Umbilical signs of peritoneal tuberculosis in children. Ind J Ped 2012; 79(9):1192-6

16. . Walia, D., Singla, A., Singla, D., \& Kaur, R. (2017). Patent Vitellointestinal Duct with Patent Urachus Presenting as Umbilical Discharge. JOURNAL OF CLINICAL AND DIAGNOSTIC RESEARCH. https://doi.org/10.7860/jcdr/2017/24726.9366

17. Shruthi K, Haridarshan, S., \& Rajagopalan, S. (2018). Urachal remnants presenting as an umbilical sinus in middle age: a rare case report. International Surgery Journal, 5(1), 330-332.

18. Siow, S., Sha, H., \& Wong, C. (2016). Abdominal tuberculosis manifested as tuberculosis of the urachal sinus in an adolescent and the role of laparoscopy in the management: a rare case report. BMC Infectious Diseases, 16(1). https://doi.org/10.1186/s12879-016-1405-6

19. McClenathan, J. (2002). Umbilical epidermoid cyst: an unusal cause of umbilical symptoms. Can J Surg, 45(4), 303-304. 